\title{
Nanocząsteczki - nowa droga w kształtowaniu parametrów świeżych i stwardniałych zaczynów cementowych
}

\begin{abstract}
Zwiększające się wymagania odnośnie właściwości zaczynu i kamienia cementowego sprawiają, iż konieczne jest poszukiwanie niekonwencjonalnych rozwiązań i materiałów, które zapewnią uzyskanie jak najlepszych efektów. Przy stosowaniu odpowiednich ilości nanocząsteczek możliwe jest zaprojektowanie zaczynu cementowego o dobrych parametrach reologicznych, dużej wytrzymałości, a równocześnie charakteryzującego się niską filtracją. W wyniku przeprowadzonych w INiG - PIB badań nad wpływu nanotlenku krzemu i nanotlenku glinu na właściwości zaczynu cementowego można stwierdzić, że komponenty te powodują wyraźną poprawę parametrów stwardniałego zaczynu cementowego. Na uwagę zasługuje fakt, że kamienie cementowe uzyskane z zaczynów zawierających nanokomponenty charakteryzowały się wysokimi wartościami wytrzymałości na ściskanie, co jest spowodowane upakowaniem się w przestrzeniach porowych nanocząsteczek o bardzo małych rozmiarach. Nawet w temperaturze $25^{\circ} \mathrm{C}$ próbki z nano- $\mathrm{SiO}_{2}$ i nano- $\mathrm{Al}_{2} \mathrm{O}_{3}$ osiągały bardzo wysokie wartości wytrzymałości na ściskanie, dochodzące w niektórych przypadkach nawet do $30 \mathrm{MPa}$ po 2 dniach i prawie $50 \mathrm{MPa}$ po 28 dniach. W porównaniu z kamieniem cementowym bez dodatku nanocząsteczek jest to przyrost wytrzymałości na ściskanie sięgający kilkudziesięciu procent. Stwardniałe zaczyny cementowe $\mathrm{z}$ dodatkiem nanocząsteczek wykazywały również znacznie bardziej zwartą mikrostrukturę w porównaniu z tzw. „czystym” zaczynem bazowym. Próbki z nanocząsteczkami posiadały także bardzo niską (około $1,5 \div 2 \%$ ) zawartość porów kapilarnych, mogących tworzyć kanaliki dla przepływu mediów złożowych przez płaszcz cementowy w otworze wiertniczym. Pory o najmniejszych rozmiarach (poniżej $100 \mathrm{~nm}$ ) stanowią zdecydowaną większość $(95 \div 98 \%)$ z ogólnej ilości porów występujących w matrycy cementowej. Świadczy to o bardzo niskiej przepuszczalności dla medium złożowego w przypadku zastosowania próbek $\mathrm{z}$ dodatkami nanokomponentów. Zaprezentowane w niniejszym artykule zaczyny cementowe z nanocząsteczkami krzemu i glinu mogą być podstawą do opracowania szerokiej gamy innowacyjnych receptur zaczynów uszczelniających o podwyższonych wytrzymałościach mechanicznych i bardzo wysokiej szczelności matrycy cementowej.
\end{abstract}

Słowa kluczowe: nanokrzemionka, zaczyn cementowy, stwardniały zaczyn cementowy, wytrzymałość mechaniczna.

\section{Nanoparticles - new direction in improvement of liquid and hard cement slurries}

Increasing requirements on the properties of slurry and set cement slurry enforce seeking unconventional solutions and materials that will ensure obtaining the best results. By using appropriate amounts of nanoparticles, it will be possible to design a cement slurry with good rheological parameters, high compressive strength, and at the same time low filtration. The results of research carried out in The Oil and Gas Institute - National Research Institute, concerning the influence of nanosilica and nano alumia oxide (nano- $\mathrm{Al}_{2} \mathrm{O}_{3}$ ) on the properties of cement slurry, confirmed that the addition of nanoparticles significantly improves the parameters of set cements. Noteworthy is the fact that the cement stones prepared from cement slurries with nanoparticles were characterized by high values of compressive strength, which was caused by packing of the small size nanoparticles in the pore spaces. Even at temperatures of $25^{\circ} \mathrm{C}$ cement samples with nano- $\mathrm{SiO}_{2}$ and nano- $\mathrm{Al}_{2} \mathrm{O}_{3}$ achieved high compressive strength, as high as $30 \mathrm{MPa}$ after 2 days and almost $50 \mathrm{MPa}$ after 28 days. Compared to the samples base without the addition of nanoparticles, an increase of compressive strength of tens of percent up could be observed. Equate to base cement slurry, set cements with nanoparicles addition were characterized by more compact microstructure. Pore distribution of cement stone samples with nanoparticles were characterized by a small number of capillary pores (in the range $1.5 \div 2 \%$ ), which could cause channels for the flow of reservoir fluids through the cement sheath in the borehole. Pores of the smallest 
sizes (below $100 \mathrm{~nm}$ ), made up a vast majority (95-98\%) of the total pores in the cement matrix, which prove their low permeability for reservoir fluids. Presented in this article, cement slurries with the addition of nanosilica and nano alumia oxide can be the basis for the development of a wide range of innovative recipes sealing slurries with higher mechanical strength and very high tightness of the cement matrix.

Key words: nanosilica, cement slurry, set cement, mechanic strength.

\section{Wprowadzenie}

Zabieg cementowania w otworach wiertniczych ma dwa główne cele: ograniczanie migracji płynów (np. wód słodkich, solanek, gazu ziemnego, ropy naftowej) między strefami w formacjach skalnych oraz uzyskanie trwałego połączenia kamienia cementowego w przestrzeni pierścieniowej pomiędzy ścianą otworu wiertniczego a kolumną rur okładzinowych. Poza tym powstający płaszcz cementowy zapobiega korozji rur, chroni je przed znacznymi obciążeniami uderzeniowymi podczas dalszego wiercenia oraz uszczelnia strefy ucieczek płuczki i inne odcinki otworu, w których występują komplikacje podczas wiercenia. Przy wyborze technologii cementowania oraz przy projektowaniu rodzaju zaczynu cementowego należy mieć na uwadze konieczność zapewnienia jak najlepszej szczelności między kolumną rur okładzinowych a poziomem skał zbiornikowych. W każdym projekcie cementowania niezbędne jest uwzględnienie faktu, iż stwardniały zaczyn cementowy w otworze wiertniczym narażony jest na działanie ekstremalnych warunków.
Należą do nich m.in.: wysoka temperatura i ciśnienie panujące na dużych głębokościach czy też obecność silnie zmineralizowanych solanek złożowych niekorzystnie wpływających na trwałość powstałego kamienia cementowego. Trzeba również pamiętać, że zaczyn cementowy musi posiadać odpowiednią płynność przez dostatecznie długi okres czasu, aby można było przetłoczyć go przez kolumnę rur okładzinowych i wytłoczyć w pozarurową przestrzeń pierścieniową. Świeży zaczyn powinien charakteryzować się również dobrymi parametrami reologicznymi, niską filtracją i brakiem odstoju wody, odpowiednim czasem wiązania, a powstały kamień cementowy - brakiem przepuszczalności dla gazu i dużą wytrzymałością mechaniczną [15].

$\mathrm{W}$ artykule przedstawiono wyniki badań innowacyjnych zaczynów cementowych wzbogaconych o dodatek nanocząsteczek n-SiO ${ }_{2}$ i n- $\mathrm{Al}_{2} \mathrm{O}_{3}$, które mogą w najbliższych latach być użyte $\mathrm{w}$ procesie uszczelniania rur okładzinowych $\mathrm{w}$ otworach wiertniczych o temperaturze dennej około $20 \div 40^{\circ} \mathrm{C}$.

\section{Nanomateriały jako dodatek do zaczynów cementowych}

Nanomateriałami nazywamy taki rodzaj materiałów, w których przynajmniej jeden z wymiarów przestrzennych jest mniejszy niż $100 \mathrm{~nm}$ [11]. Nanocząsteczki możemy podzielić ze względu na wymiar w skali nano na [4]:

- całe w skali nano (0-D),

- dwa wymiary w skali nano (1-D),

- jeden w skali nano (2-D),

- żaden w skali nano (3-D).

Najpopularniejszym materiałem stosowanym jako rdzeń w nanostrukturach jest krzemionka, a to głównie dzięki bardzo korzystnym właściwościom technologicznym [16]. Należy do nich zaliczyć: transparentność w zakresie widzialnym, chemiczną bierność, odporność na koagulację (niska stała Hamakera) oraz brak wpływu na reakcje redoks przebiegające na powierzchni rdzenia krzemionkowego. Sferyczne nanocząstki krzemionkowe, o średnicy od $5 \mathrm{~nm}$ do kilku $\mu \mathrm{m}$, mogą być otrzymywane za pomocą takich metod jak [8] np.:

- odwróconych miceli oraz zol-żel,

- syntezy w płomieniowym reaktorze aerozoli (ang. flame aerosol reactor),
- wysokotemperaturowej hydrolizy $\mathrm{SiCl}_{4}$ w reaktorze płomieniowym,

- termicznego utleniania tetraetoksysilanu (TEOS) w fazie gazowej,

- matrycy koloidalnej i matrycy na bazie surfaktantu,

- mikroemulsji woda w oleju,

- rozdrabniania w młynie kulowym,

- ciągłej hydrotermicznej syntezy mikrofalowej.

Techniki te pozwalają na otrzymywanie nanocząstek o określonych wymiarach i dyspersji rozkładu ich wielkości: większej bądź mniejszej - w zależności od zastosowanej metody syntezy. Techniką najczęściej wybieraną przez naukowców pracujących z nanocząstkami krzemionkowymi jest metoda zol-żel, a dokładniej metoda Stöbera [14] i jej modyfikacje. Procedura opracowana przez Stöbera była pierwszą metodą otrzymywania wysoce sferycznych, jednorodnie zdyspergowanych nanocząstek krzemionkowych o dobrej jakości, które mogły być użyte między innymi jako półprodukt do uzyskiwania bardziej zaawansowanych nanomateriałów. Metoda Stöbera jest relatywnie prosta, efektywna i bardzo 
dobrze sprawdza się w przypadku syntezy dużych cząstek krzemionkowych (o średnicach od setek nm do kilku $\mu \mathrm{m}$ ). Jednakże w przypadku mniejszych cząstek o średnicach od 5 do 50 nm wyniki nie zawsze są zadowalające.

Typowa procedura otrzymywania nanocząstek krzemionkowych polega na wymieszaniu etanolu, wody amoniakalnej (jako katalizatora), małej ilości dejonizowanej wody, a następnie szybkim lub stopniowym wprowadzeniu do tej mieszaniny tetraetoksysilanu (TEOS, $\left.\mathrm{Si}\left(\mathrm{C}_{2} \mathrm{H}_{5} \mathrm{O}\right)_{4}\right)$ przy ciągłym mieszaniu. Mieszanie może być zastąpione użyciem ultradźwięków (łaźni ultradźwiękowej). W wyniku zachodzących reakcji następuje hydroliza wiązań $\mathrm{Si}-\mathrm{O}$ w TEOS, a następnie kondensacja utworzonych grup hydroksylowych z wytworzeniem sieci krzemionkowej-Si-O-Si- oraz wody jako dodatkowego produktu reakcji. Nanocząstki krzemionkowe otrzymywane metodą Stöbera są amorficzne, a ponadto uzyskuje się niewielki rozrzut wymiarów tych cząstek (mniejszy od 5\%) [8]. Proces przebiega według następujących ogólnych równań reakcji:

$$
\begin{aligned}
\mathrm{Si}\left(\mathrm{OC}_{2} \mathrm{H}_{5}\right)_{4}+4 \mathrm{H}_{2} \mathrm{O} & \rightarrow \mathrm{Si}(\mathrm{OH})_{4}+4 \mathrm{C}_{2} \mathrm{H}_{5} \mathrm{OH} \\
\mathrm{Si}(\mathrm{OH})_{4} & \rightarrow \mathrm{SiO}_{2}+2 \mathrm{H}_{2} \mathrm{O}
\end{aligned}
$$

Żelowanie jest skomplikowanym zjawiskiem, a jego mechanizm nie jest do końca poznany. Prawdopodobne reakcje hydrolizy i kondensacji tetraalkoksysilanów podczas procesu żelowania przedstawiono na rysunku 1 [8].

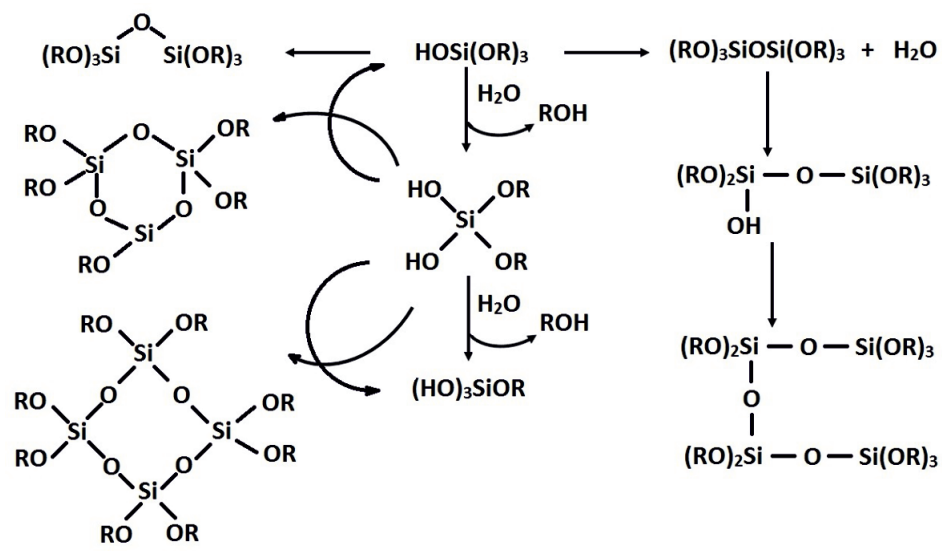

Rys. 1. Schemat możliwych reakcji tetraalkoksysilanów [8]
Procedura Stöbera umożliwia kontrolę wymiaru, porowatości oraz morfologii wytwarzanych nanocząstek. Poprzez zmianę stosunku TEOS do rozpuszczalnika (rozcieńczenie), ilości wody oraz ilości katalizatora $\left(\mathrm{NH}_{3} \mathrm{aq}\right)$, czyli stężenia reagentów, można kontrolować wymiary otrzymywanych nanocząstek, które wahają się od kilkunastu-kilkudziesięciu nm do kilku $\mu \mathrm{m}$ [8].

Od jakiegoś czasu prowadzone są badania nad zastosowaniem nanomateriałów jako dodatków do zaczynów cementowych. Największym zainteresowaniem cieszą się nanotlenki krzemionki, glinu oraz żelaza. Literatura [1, 3 , 9-11] podaje przykłady zastosowania nanotlenku glinu, wpływającego w pewnej mierze na wzrost wytrzymałości na ściskanie, a także dodatków nano- $\mathrm{SiO}_{2}$ i nano- $\mathrm{Fe}_{2} \mathrm{O}_{3}-$ poprawiających wytrzymałość na ściskanie i zginanie matrycy cementowej. Zauważono, że dodatek nanokrzemionki poza poprawą właściwości mechanicznych kamieni cementowych wpływa także w pewnym stopniu na zmniejszenie filtracji [11].

Wytrzymałość na ściskanie i zginanie zaczynu cementowego $\mathrm{z}$ dodatkiem nano- $\mathrm{SiO}_{2}$ i nano- $\mathrm{Fe}_{2} \mathrm{O}_{3}$ okazuje się być wyższa niż wytrzymałość zwykłego zaczynu cementowego o tym samym stosunku w/c, co wykazuje, że dodatek nanocząsteczek wpływa wzmacniająco na zaczyn cementowy. Oprócz poprawy wytrzymałości dodatek nano- $\mathrm{Fe}_{2} \mathrm{O}_{3}$ poprawia zdolność monitorowania naprężeń w kamieniu cementowym. Zdolność samodiagnostyki wzrasta z ilością dodanego nano- $\mathrm{Fe}_{2} \mathrm{O}_{3}$, tak więc zaczyn $\mathrm{z}$ dodatkiem nano- $\mathrm{Fe}_{2} \mathrm{O}_{3}$ jest tzw. ,inteligentnym” materiałem, który może monitorować i sygnalizować powstające naprężenia $[1,3,9-11]$.

Niektórzy autorzy prowadzili również badania nad wpływem nanorurek węglowych na parametry mechaniczne stwardniałego zaczynu cementowego. Jedni [12] sugerują, że dodatek nanorurek węglowych nie wpływa znacząco na wzrost wytrzymałości mechanicznej, natomiast inni [11], że dodatek nawet $0,05 \%$ nanorurek powoduje wzrost wytrzymałości na ściskanie stwardniałego zaczynu cementowego nawet do $70 \%$.

\section{Mechanizm działania nanocząsteczek}

Kamień cementowy zbudowany jest z małych ziaren uwodnionego żelu krzemianów wapnia i dużych kryształków uwodnionych produktów hydratacji, między którymi znajdują się nanopory i pory kapilarne. Jest to miejsce idealne dla nanocząsteczek, aby poprawiły właściwości zaczynu cementowego $[5,6]$. Jednakże z powodu dużej energii powierzchniowej nanocząsteczki łatwo łączą się w agregaty, co wywołuje znaczne trudności w ich dyspersji (zwłaszcza w przypadku większych ilości). W tej sytuacji powstawanie agregatów nanocząsteczek powoduje tworzenie się pustych przestrzeni, które wpływają na osłabienie właściwości mechanicznych zaczynów cementowych [7].

Mechanizm poprawy skompaktowania mikrostruktury i wzrostu wytrzymałości kamieni cementowych można przedstawić w następujący sposób. Kiedy małe ilości nanocząsteczek zostaną równomiernie rozproszone w zaczynie cemen- 
towym, produkty hydratacji cementu będą się osadzać na nanocząsteczkach ze względu na ich dużą energię powierzchniową i podczas hydratacji zaczną wzrastać na nich do postaci konglomeratów zawierających nanocząsteczki jako jądra. Nanocząsteczki zlokalizowane w zaczynie cementowym będą dodatkowo wspierać i przyspieszać hydratację cementu ze względu na ich wysoką reaktywność. Osiągając równomierne rozproszenie nanocząsteczek, można uzyskać odpowiednią mikrostrukturę $\mathrm{z}$ równomiernie rozproszonymi konglomeratami [10].

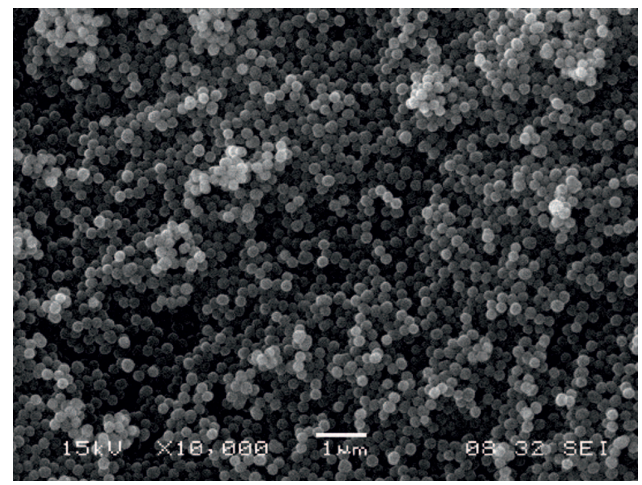

Fot. 1. Nanokrzemionka sferyczna, mikrofotografia SEM [13]
Na fotografii 1 zamieszczono przykładowy obraz otrzymany z mikroskopu skaningowego, na którym pokazane jest ułożenie cząsteczek sferycznej nanokrzemionki w matrycy [13].

W twardniejącym zaczynie cementowym nanocząsteczki wypełniają nanopory matrycy tworzącej szkielet cementowy. Ponadto nano- $\mathrm{SiO}_{2}$ reaguje $\mathrm{z} \mathrm{Ca}(\mathrm{OH})_{2}$ (reakcje pucolanowe) i powoduje powstawanie dodatkowej fazy C-S-H. Obydwa procesy zachodzą dzięki temu, że średnica nanocząsteczek jest bardzo mała oraz są one odpowiednio rozproszone w zaczynie cementowym.

W przypadku stosowania nanokrzemionki można wyróżnić cztery drogi jej działania na zaczyn cementowy. Tak więc nanokrzemionka:

- działa jako miejsce zarodkowania,

- powoduje zwiększenie powstawania żelu C-S-H poprzez występowanie reakcji pucolanowych,

- kontroluje krystalizację,

- poprawia efekt mikrowypełniania przestrzeni w matrycy cementowej.

Połączony efekt wszystkich tych mechanizmów powoduje powstawanie zwartej mikrostruktury, która jest nieprzepuszczalna dla medium złożowego [2].

\section{Wyniki badań laboratoryjnych}

Badania laboratoryjne wykonywano w INiG - PIB zgodnie z normą PN-EN ISO 10426-2 Przemyst naftowy $i$ gazowniczy - Cementy i materiaty do cementowania otworów-część 2: Badania cementów wiertniczych [17]. Sporządzono cztery receptury zaczynów cementowych: zaczyn bazowy - oznaczony jako ZB (bez dodatku nanokomponentów) oraz zaczyny z dodatkiem nanokomponentów, tj.: 0,1\% n- $\mathrm{SiO}_{2}$ (zaczyn nr 1), 1,0\% n- $\mathrm{SiO}_{2}$ (zaczyn nr 2) i 3,0\% n- $\mathrm{Al}_{2} \mathrm{O}_{3}$ (zaczyn nr 3). W tablicy 1 zamieszczono główne składniki zaczynów oraz ich podstawowe parametry technologiczne.
Analizując wyniki zamieszczone w tablicy 1, można zauważyć, że wprowadzenie do świeżych zaczynów nanokomponentów powoduje niewielkie obniżenie ich gęstości, redukcję odstoju wody oraz wydłużenie czasu gęstnienia. Po utwardzeniu próbek płynnych zaczynów cementowych sporządzono kamienie cementowe, które poddano analizie mikrostruktury, ocenie wytrzymałości mechanicznej oraz badaniom przestrzeni porowych. Na fotografiach od 2 do 5 zaprezentowano przykładowe mikrostruktury czterech próbek zaczynów, a na rysunkach 2-5 - ana-

Tablica 1. Zaczyny cementowe poddane badaniom laboratoryjnym

\begin{tabular}{|l|c|c|c|c|}
\hline Główne składniki zaczynu [\%] & Zaczyn ZB & Zaczyn nr 1 & Zaczyn nr 2 & Zaczyn nr 3 \\
\hline Współczynnik w/c (woda/cement) & 0,45 & 0,45 & 0,45 & 0,45 \\
\hline Odpieniacz & 0,20 & 0,30 & 0,30 & 0,30 \\
\hline Upłynniacz & 0,10 & 0,20 & 0,20 & 0,20 \\
\hline Nano-SiO 2 & - & 0,10 & 1,00 & - \\
\hline Nano-Al ${ }_{2} \mathrm{O}_{3}$ & - & - & - & 3,00 \\
\hline Cement portlandzki CEM 32,5 & 100,00 & 100,00 & 100,00 & 100,00 \\
\hline $\begin{array}{l}\text { Badane parametry w temperaturze } 25^{\circ} \mathrm{C} \\
\text { i przy ciśnieniu 3 MPa }\end{array}$ & Zaczyn ZB & Zaczyn nr 1 & Zaczyn nr 2 & Zaczyn nr 3 \\
\hline Gęstość zaczynu [g/cm ${ }^{3}$ ] & 1,84 & 1,83 & 1,82 & 1,82 \\
\hline Odstój wody (wolna woda) [\%] & 0,8 & 0,0 & 0,0 & 0,0 \\
\hline Czas gęstnienia, 30 Bc [h:min] & $4: 15$ & $5: 07$ & $5: 32$ & $6: 04$ \\
\hline
\end{tabular}




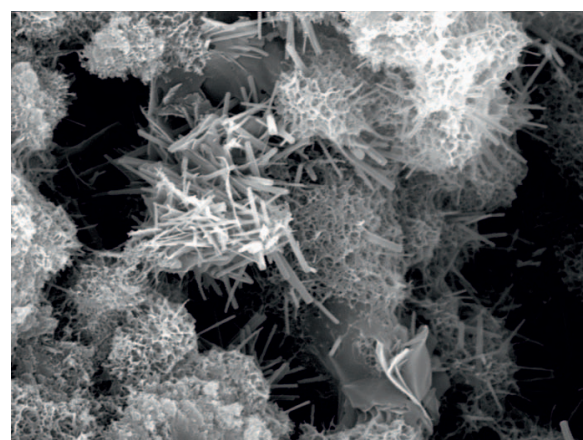

Fot. 2a. Mikrostruktura próbki ZB

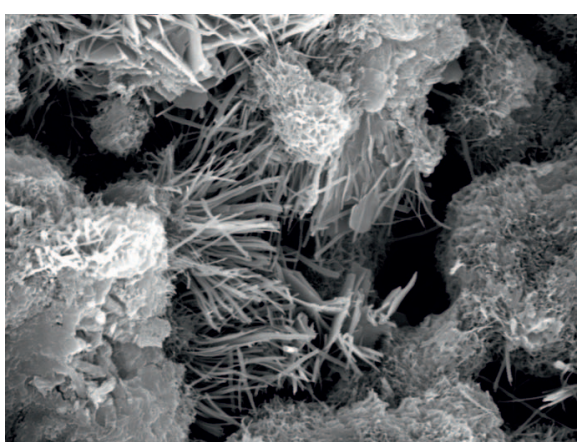

Fot. 3a. Mikrostruktura próbki nr 1

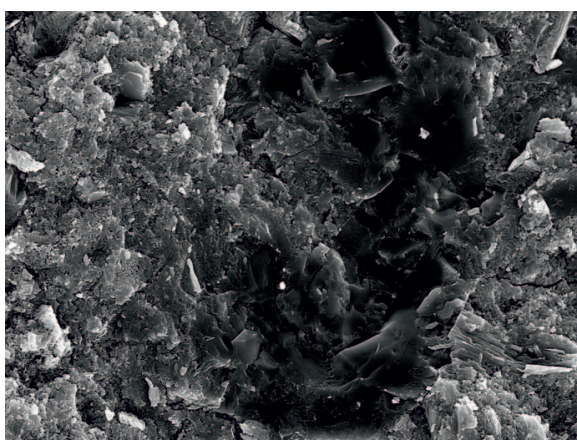

Fot. 4a. Mikrostruktura próbki nr 2

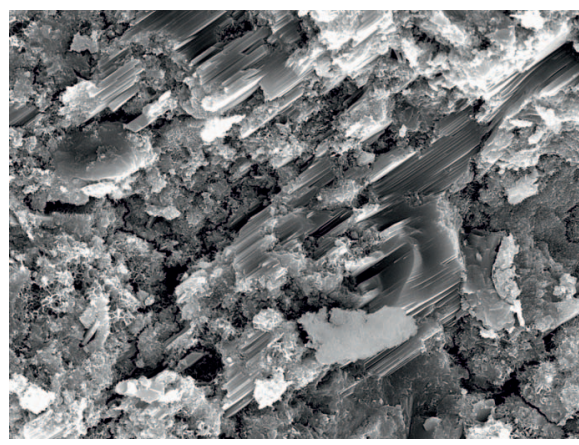

Fot. 5a. Mikrostruktura próbki nr 3

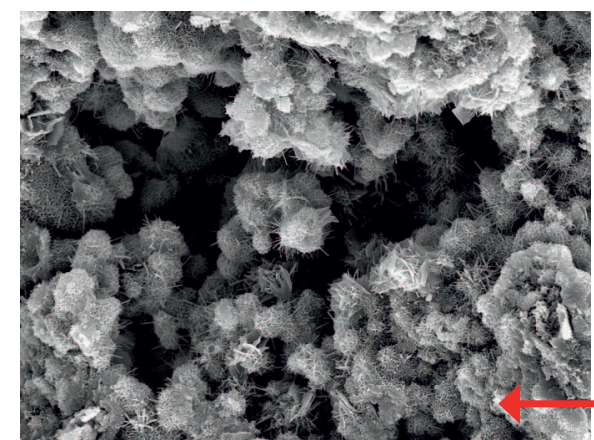

Fot. 2b. Mikrostruktura próbki ZB

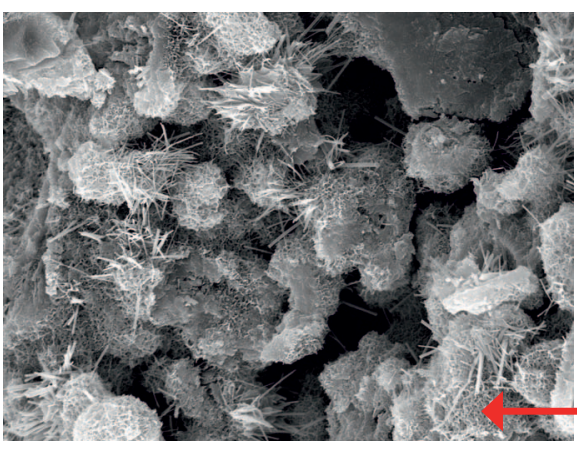

Fot. 3b. Mikrostruktura próbki nr 1

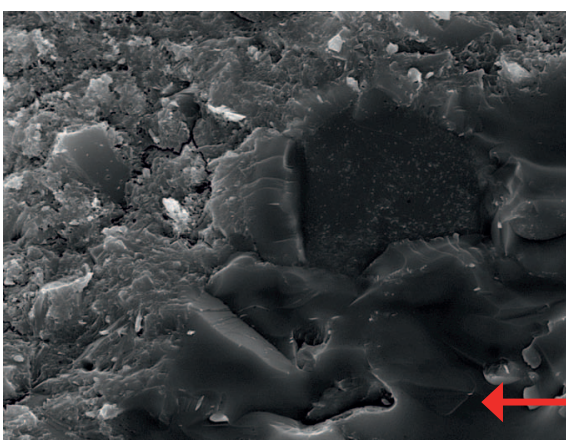

Fot. 4b. Mikrostruktura próbki nr 2

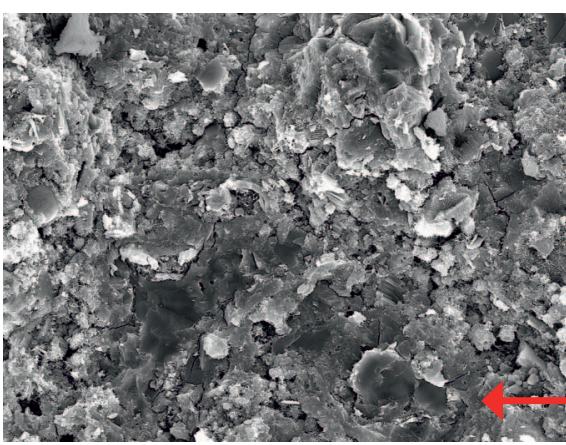

Fot. 5b. Mikrostruktura próbki nr 3

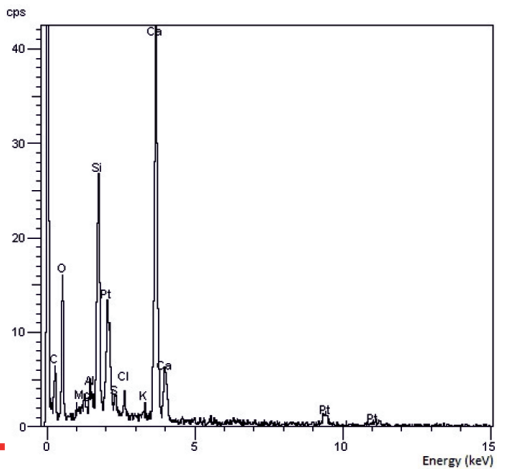

Rys. 2. Analiza pierwiastkowa próbki ZB w punkcie oznaczonym strzałką*

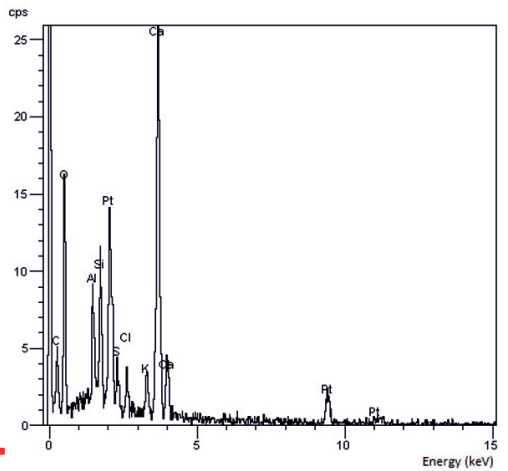

Rys. 3. Analiza pierwiastkowa próbki nr $1 \mathrm{w}$ punkcie oznaczonym strzałką

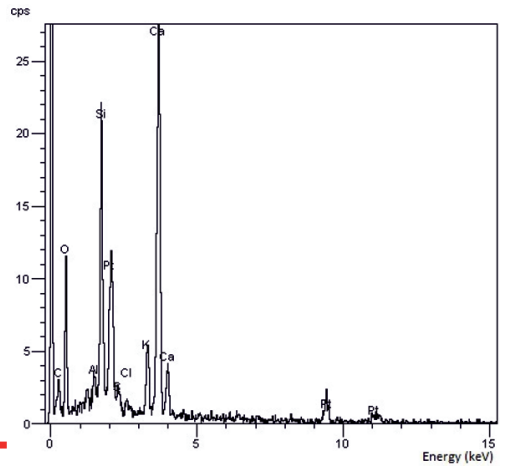

Rys. 4. Analiza pierwiastkowa próbki nr 2 w punkcie oznaczonym strzałką

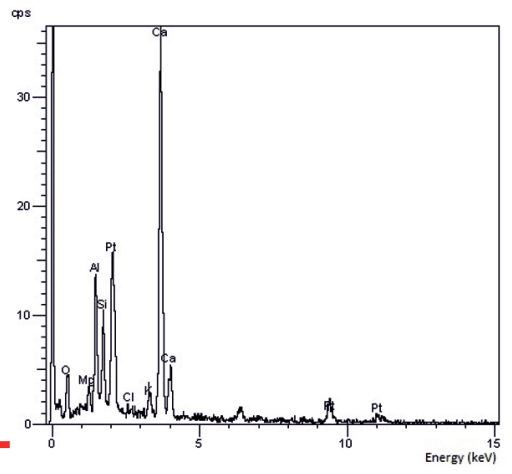

Rys. 5. Analiza pierwiastkowa próbki nr 3 w punkcie oznaczonym strzałką

\footnotetext{
* Obecność platyny na rysunkach od 2 do 5 jest spowodowana napylaniem przygotowywanych do badań stwardniałych zaczynów.
} 
lizę pierwiastkową tych próbek. Fotografie próbek wykonano za pomocą mikroskopii skaningowej. $\mathrm{Na}$ fotografiach 2a i $2 \mathrm{~b}$ widoczna jest mikrostruktura zaczynu bazowego ZB bez dodatku nanocząstek. Można tam dostrzec pory o dość dużych rozmiarach, które mogą tworzyć kanaliki w płaszczu cementowym i powodować ewentualny przepływ gazu w przestrzeni pierścieniowej. Po wprowadzeniu do próbki $0,1 \% \mathrm{n}-\mathrm{SiO}_{2}$ struktura stwardniałego zaczynu uległa pewnemu zagęszczeniu (fotografie 3a i 3b), jednak nadal widoczne są wyraźne obszary przestrzeni porowych. Na fotografiach $4 \mathrm{a}$ i $4 \mathrm{~b}$ oraz $5 \mathrm{a}$ i $5 \mathrm{~b}$ pokazana jest znacznie bardziej zwarta mikrostruktura stwardniałych zaczynów zmodyfikowanych dodatkami nanocząsteczek tlenków krzemu $\left(1 \% \mathrm{n}-\mathrm{SiO}_{2}\right)$ i glinu $\left(3 \% \mathrm{n}-\mathrm{Al}_{2} \mathrm{O}_{3}\right)$.

W mikrostrukturze tych próbek nie występują obszary makroporów, a stwardniałe zaczyny wykazują bardzo wysoką szczelność. Na rysunku 4 widoczne są wyraźne udziały krzemu ( $\mathrm{Si}$ ) i wapnia (Ca) w strukturze matrycy cementowej próbki nr 2 (z dodatkiem $1 \%$ nano- $\mathrm{SiO}_{2}$ ). Wysoki udział glinu (Al), krzemu ( $\mathrm{Si}$ ) oraz wapnia $(\mathrm{Ca})$ zarejestrowano na rysunku 5 podczas analizy próbki $\mathrm{nr} 3$ (z dodatkiem 3\% nano- $\mathrm{Al}_{2} \mathrm{O}_{3}$ ).

Na rysunku 6 zamieszczono wyniki badań wytrzymałości na ściskanie omawianych próbek. Na szczególną uwagę zasługuje zaczyn $\mathrm{nr} 2 \mathrm{z}$ dodatkiem $1 \%$ nano- $\mathrm{SiO}_{2}$, który po 28 dniach cechował się bardzo wysoką wytrzymałością (dochodzącą do około $50 \mathrm{MPa}$ ), co sprawia, iż może on znaleźć zastosowanie $\mathrm{w}$ procesie uszczelniania kolumn rur okładzinowych w szczególnie wymagających warunkach technologicznych.

Narastanie intruzji od rozmiaru porów

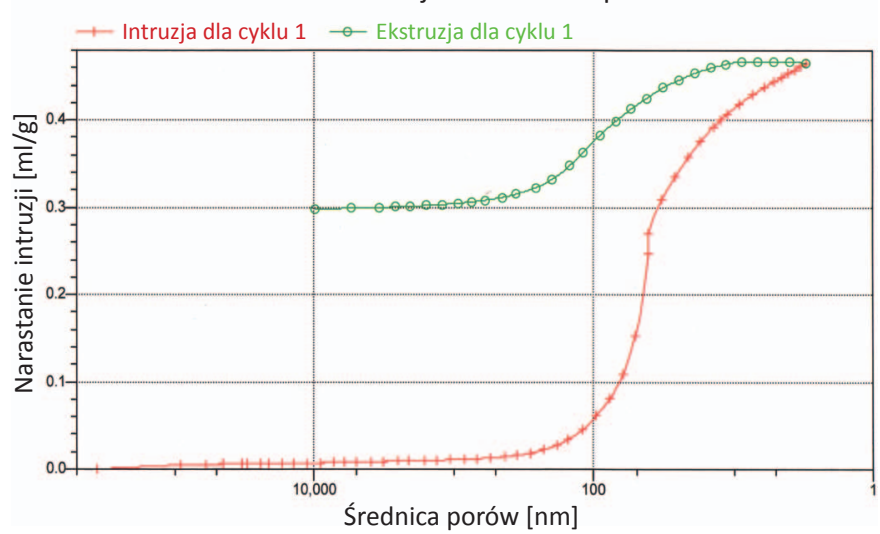

Rys. 7. Rozkład porów dla próbki ZB (porowatość ogólna: 41,8\%)
Na rysunkach od 7 do 10 zamieszczono krzywe kumulacyjne porowatości badanych próbek stwardniałych zaczynów cementowych. Porowatość próbki zaczynu bazowego ZB (rysunek 7) wynosiła 41,8\%. Pory największe (o średnicy powyżej $10000 \mathrm{~nm}$ ) stanowiły około 1,5\% całkowitej ilości porów, pory o wielkości od 10000 do $100 \mathrm{~nm}$ zajmowały około $12 \%$ całości. Najmniejsze pory, o średnicy poniżej $100 \mathrm{~nm}$, stanowiły około 86\% całości porów. W przypadku próbek zawierający nanokomponenty (rysunki 8, 9, 10) zaobserwowano wyraźnie niższą porowatość ogólną (wynoszącą około $30 \div 32 \%$ ) oraz znacznie korzystniejszy rozkład średnic porowych (pory największych rozmiarów stanowią znikomą ilość ogólnej liczby porów). Na szczególną uwagę zasługuje próbka $\mathrm{nr} 2 \mathrm{z}$ dodatkiem 1\% n- $\mathrm{SiO}_{2}$ (rysunek 9), gdzie powyżej $98 \%$ całości porów stanowią pory najmniejsze, tj. o średnicach poniżej $100 \mathrm{~nm}$.

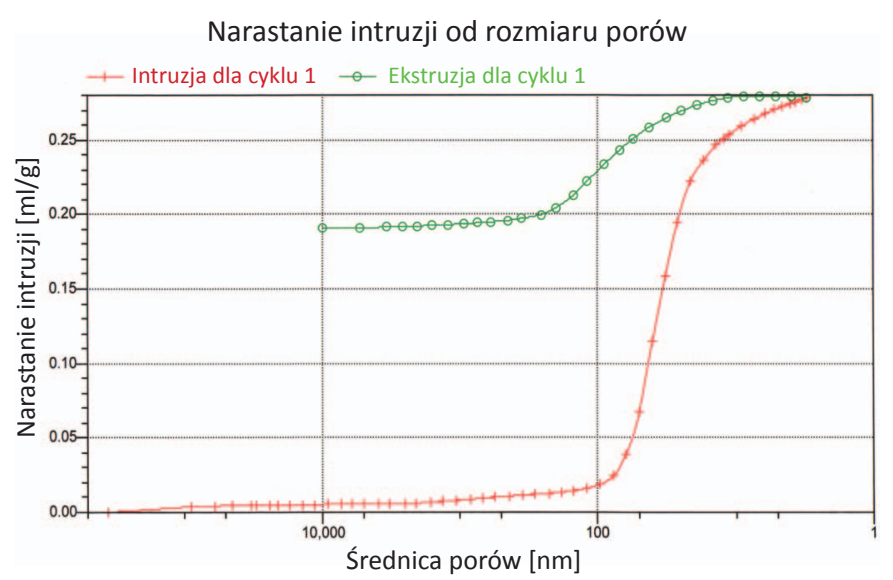

Rys. 8. Rozkład porów dla próbki nr 1 (porowatość ogólna: 32,3\%)

\begin{tabular}{|c|c|c|c|c|c|c|c|}
\hline Średnica porów & $>10000 \mathrm{~nm}$ & $10000-100 \mathrm{~nm}$ & $<100 \mathrm{~nm}$ & Średnica porów & $>10000 \mathrm{~nm}$ & $10000-100 \mathrm{~nm}$ & $<100 \mathrm{~nm}$ \\
\hline Ilość [\%] & 1,5 & 12,1 & 86,4 & Ilość [\%] & 1,9 & 4,8 & 93,3 \\
\hline
\end{tabular}


Narastanie intruzji od rozmiaru porów

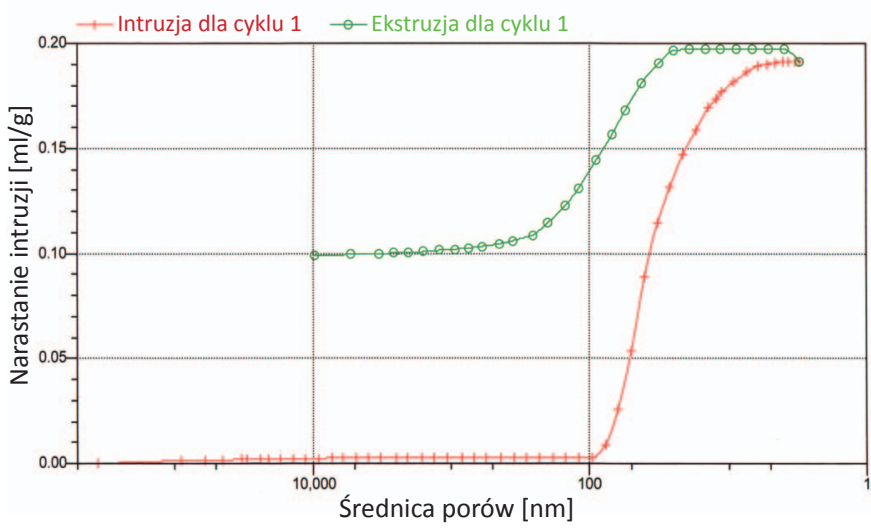

Rys. 9. Rozkład porów dla próbki nr 2 (porowatość ogólna: 30,1\%)
Narastanie intruzji od rozmiaru porów

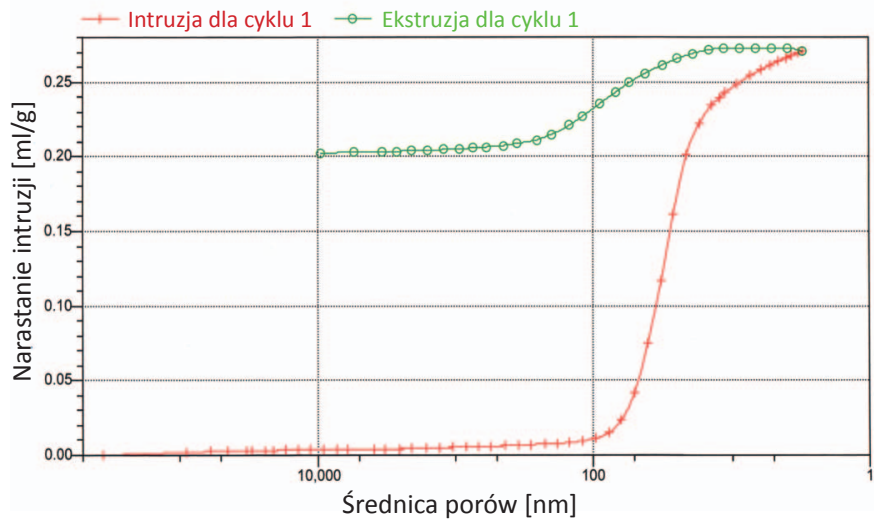

Rys. 10. Rozkład porów dla próbki nr 3 (porowatość ogólna: 31,4\%)

\begin{tabular}{|c|c|c|c|c|c|c|c|}
\hline Średnica porów & $>10000 \mathrm{~nm}$ & $10000-100 \mathrm{~nm}$ & $<100 \mathrm{~nm}$ & Średnica porów & $>10000 \mathrm{~nm}$ & $10000-100 \mathrm{~nm}$ & $<100 \mathrm{~nm}$ \\
\hline Ilość [\%] & 1,5 & 0,2 & 98,3 & Ilość [\%] & 1,4 & 2,8 & 95,8 \\
\hline
\end{tabular}

\section{Podsumowanie}

Analizując uzyskane wyniki badań laboratoryjnych wpływu nanotlenku krzemu i nanotlenku glinu na właściwości zaczynu cementowego, można stwierdzić, że komponenty te powodują wyraźną poprawę parametrów stwardniałego zaczynu cementowego. Na uwagę zasługuje fakt, że kamienie cementowe uzyskane z zaczynów zawierających nanokomponenty charakteryzowały się wysokimi wartościami wytrzymałości na ściskanie, co jest spowodowane upakowaniem się w przestrzeniach porowych nanocząsteczek o bardzo małych rozmiarach. Nawet w temperaturze $25^{\circ} \mathrm{C}$ próbki z nano- $\mathrm{SiO}_{2}$ i nano- $\mathrm{Al}_{2} \mathrm{O}_{3}$ osiągały bardzo wysokie wartości wytrzymałości na ściskanie, dochodzące w niektórych przypadkach nawet do $30 \mathrm{MPa}$ po 2 dniach i prawie $50 \mathrm{MPa}$ po 28 dniach. W porównaniu z kamieniem cementowym bez dodatku nanocząsteczek jest to przyrost wytrzymałości na ściskanie sięgający kilkudziesięciu procent.

Stwardniałe zaczyny cementowe $\mathrm{z}$ dodatkiem nanoczą- steczek wykazywały również znacznie bardziej zwartą mikrostrukturę w porównaniu z tzw. „czystym” zaczynem bazowym. Próbki z nanocząsteczkami posiadały także bardzo niską (około $1,5 \div 2 \%$ ) zawartość porów kapilarnych, mogących tworzyć kanaliki dla przepływu mediów złożowych przez płaszcz cementowy w otworze wiertniczym. Pory o najmniejszych rozmiarach (poniżej $100 \mathrm{~nm}$ ) stanowią zdecydowaną większość $(95 \div 98 \%)$ z ogólnej ilości porów występujących w matrycy cementowej. Świadczy to o bardzo niskiej przepuszczalności dla medium złożowego w przypadku zastosowania próbek z dodatkami nanokomponentów.

Zaprezentowane w niniejszym artykule zaczyny cementowe z dodatkiem nanocząsteczek krzemu i glinu mogą być podstawą do opracowania szerokiej gamy innowacyjnych receptur zaczynów uszczelniających o podwyższonych wytrzymałościach mechanicznych i bardzo wysokiej szczelności matrycy cementowej.

Prosimy cytować jako: Nafta-Gaz 2016, nr 12, s. 1084-1091, DOI: 10.18668/NG.2016.12.11

Artykuł przysłany do Redakcji 27.10.2016 r. Artykuł zatwierdzony do druku 21.11.2016 r.

Artykuł powstał na podstawie pracy statutowej pt. Analiza wpływu dodatków nanoczasteczek na mikrostrukturę stwardniałych zaczynów cementowych - praca INiG - PIB na zlecenie MNiSW; nr zlecenia: 0041/KW/16/01, nr archiwalny: DK-4100-41/2016.

\section{Literatura}

[1] Birgisson B., Beatty C.L.: Nanomodified Concrete Additive and High Performance Cement Paste and Concrete Therefrom. International Patent Applicaton, PCT/US2007/073430.

[2] Birgisson B., Mukhopadhyay A.K., Geary G., Khan M., Sobolev K.: Nanotechnology in Concrete Materials: A Synopsis. Transportation Research Circular, Nr E-C170, December 2012.

[3] Campillo I., Guerrero A., Dolado J.S., Porro A., Ibanez J.A.,
Goni S.: Improvement of Initial Mechanical Strenght by $\mathrm{Na}$ noalumina in Belite Cements. Materials Letters 2007, vol. 61, s. 1889-1892.

[4] Czarnecki L.: Nanotechnologia w budownictwie; www.inzynierbudownictwa.pl/drukuj,4234 (dostęp: kwiecień 2016).

[5] Dębińska E.: Niekonwencjonalne zaczyny cementowe z dodatkiem nanokrzemionki. Nafta-Gaz 2015, nr 5, s. 290-300. 
[6] Dębińska E.: Wplyw nanokrzemionki na parametry mechaniczne kamienia cementowego. Nafta-Gaz 2014, nr 4, s. 229-235.

[7] Guskos N., Zolnierkiewicz G., Typek J., Blyszko J., Kiernozycki W., Narkiewicz U.: Ferromagnetic Resonance and Compressive Strength Study of Cement Mortars Containing Carbon Encapsulated Nickel and Iron Nanoparticles. Reviews on Advanced Materials Science 2010, vol. 23, s. 113-117.

[8] Jankiewicz B.J., Choma J., Jamiola D., Jaroniec M.: Nanostruktury krzemionkowo-metaliczne. Wiadomości Chemiczne 2010, vol. 64, s. 11-12.

[9] Li H., Xiao H., Ou J.: A Study on Mechanical and Pressure-Sensitive Properties of Cement Mortar with Nanophase Materials. Cement and Concerne Research 2004, vol. 34, s. $435-438$

[10] Li H., Xiao H., Ou J.: Microstructure of Cement Mortar with Nano-Particles. Composites: Part B 2004, vol. 35, s. 185-189.

[11] Patil R., Deshpande A.: Use of Nanomaterials in Cementing Applications. Conference materials: SPE International Oilfield Nanotechnology Conference and Exhibition, Noordwijk, The Netherlands, 12-14.06.2012, s. 120-123.

[12] Santra A., Boul P.J., Pang X.: Influence of Nanomaterials in Oilwell Cement Hydration and Mechanical Properties. Conference materials: SPE International Oilfield Nanotechnology Conference and Exhibition, Noordwijk, The Netherlands, 12-14.06.2012, s. 177-189.

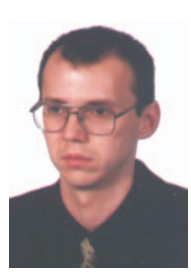

\section{Dr inż. Marcin RZEPKA}

Kierownik Laboratorium Zaczynów Uszczelniających w Zakładzie Technologii Wiercenia.

Instytut Nafty i Gazu - Państwowy Instytut Badawczy

ul. Lubicz $25 \mathrm{~A}$

31-503 Kraków

E-mail: marcin.rzepka@inig.pl
[13] Strona internetowa: http://docplayer.p1/4607780-Nanokrzemionkisferyczne-do-zastosowan-high-tech.html (dostęp: 12.10.2016).

[14] Strona internetowa: http://miesiecznikchemik.pl/wp-content/ uploads/2015/02/chemik_2014_09-3.pdf(dostęp: 21.10.2016).

[15] Uliasz M., Zima G., Błaż S., Jasiński B.: Ocena właściwości cieczy wiertniczych $w$ aspekcie zapobiegania migracji gazu w otworach na przedgórzu Karpat. Nafta-Gaz 2015, nr 1, s. $11-17$.

[16] Wilk K., Kasza P., Czupski M.: Zastosowanie nanocieczy jako dodatków wspomagajacych proces wypierania ropy naftowej. Nafta-Gaz 2014, nr 1, s. 14-20.

\section{Akty prawne i normatywne}

[17] Norma PN-EN ISO 10426-6 Przemyst naftowy i gazowniczy. Cementy i materiaty do cementowania otworów. Czesść 2: Badania cementów wiertniczych, maj 2006.

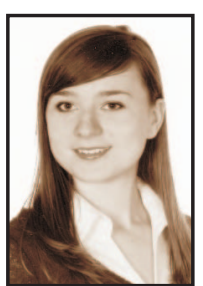

Mgr Edyta DĘBIŃSKA

Absolwentka Uniwersytetu Marii Curie-Skłodowskiej w Lublinie. Była pracownikiem Instytutu Nafty i Gazu Oddział w Krośnie. Zajmowała się badaniami zaczynów cementowych stosowanych do uszczelniania rur okładzinowych w otworach wiertniczych. Zmarła 22 lipca 2016 roku.

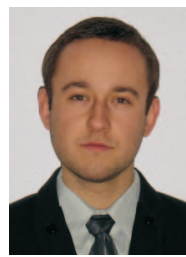

Dr inż. Marcin KREMIENIEWSKI

Adiunkt w Zakładzie Technologii Wiercenia.

Instytut Nafty i Gazu - Państwowy Instytut Badawczy ul. Lubicz 25 A

31-503 Kraków

E-mail:marcin.kremieniewski@inig.pl

\section{OFERTA}

\section{ZAKŁAD TECHNOLOGII WIERCENIA}

Zakres działania:

- opracowywanie składów i technologii sporządzania płuczek wiertniczych, cieczy do dowiercania, opróbowania i rekonstrukcji odwiertów, zaczynów cementowych i mieszanin wiążących dla różnych warunków geologiczno-technicznych wiercenia;

- $\quad$ kompleksowe badania i ocena nowych rodzajów środków chemicznych, materiałów płuczkowych i wiążących, przeznaczonych do sporządzania i regulowania właściwości płuczek wiertniczych i zaczynów cementowych;

- pomiary parametrów technologicznych cieczy wiertniczych i kamienia cementowego w warunkach normalnej i wysokiej temperatury oraz ciśnienia;

- badania wpływu płuczek wiertniczych na przewiercane skały;

- dobór płuczek wiertniczych, zaczynów cementowych, cieczy buforowych w celu poprawy skuteczności cementowania otworów wiertniczych;

- badania serwisowe dla bieżących zabiegów cementowania;

- $\quad$ specjalistyczne badania laboratoryjne dotyczące oznaczania: współczynnika tarcia cieczy wiert-

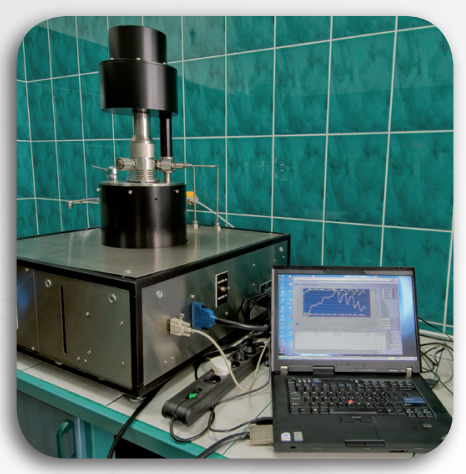
niczych i napięcia powierzchniowego na granicy faz, czystości i temperatury krystalizacji solanek, typu emulsji, sedymentacji fazy stałej, efektywności wynoszenia zwiercin w otworach kierunkowych i poziomych oraz wypłukiwania osadów iłowych ze skał przed zabiegiem cementowania, odporności na migrację gazu w wiążącym zaczynie cementowym w warunkach otworopodobnych, wczesnej wytrzymałości na ściskanie kamienia cementowego, odporności korozyjnej kamienia cementowego w różnym środowisku złożowym, porowatości oraz przepuszczalności dla gazu kamienia cementowego i skał, zawartości związków chemicznych w cieczach wiertniczych, stopnia toksyczności środków chemicznych i cieczy wiertniczych przy użyciu bakterii bioindykatorów;

- badania właściwości fizyczno-mechanicznych skał pod kątem ich zwiercalności.

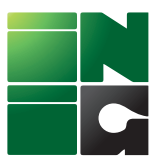

